\title{
The Bryopsis hypnoides Plastid Genome: Multimeric Forms and Complete Nucleotide Sequence
}

\author{
Fang $L \ddot{u}^{1,39}$, Wei $X \ddot{u ̈}^{2,39}$, Chao Tian ${ }^{1}$, Guangce Wang ${ }^{1 *}$, Jiangfeng Niu' ${ }^{1}$ Guanghua Pan ${ }^{4}$, Songnian $\mathrm{Hu}^{3}$ \\ 1 Institute of Oceanology, The Chinese Academy of Sciences (IOCAS), Qingdao, China, 2 Beijing Genomics Institute, The Chinese Academy of Sciences (BGICAS), Beijing, \\ China, 3 Graduate University of the Chinese Academy of Sciences, Beijing, China, $\mathbf{4}$ College of Marine Science and Engineering, Tianjin University of Science and \\ Technology, Tianjin, China
}

\begin{abstract}
Background: Bryopsis hypnoides Lamouroux is a siphonous green alga, and its extruded protoplasm can aggregate spontaneously in seawater and develop into mature individuals. The chloroplast of $B$. hypnoides is the biggest organelle in the cell and shows strong autonomy. To better understand this organelle, we sequenced and analyzed the chloroplast genome of this green alga.

Principal Findings: A total of 111 functional genes, including 69 potential protein-coding genes, 5 ribosomal RNA genes, and 37 tRNA genes were identified. The genome size (153,429 bp), arrangement, and inverted-repeat (IR)-lacking structure of the B. hypnoides chloroplast DNA (cpDNA) closely resembles that of Chlorella vulgaris. Furthermore, our cytogenomic investigations using pulsed-field gel electrophoresis (PFGE) and southern blotting methods showed that the $B$. hypnoides cpDNA had multimeric forms, including monomer, dimer, trimer, tetramer, and even higher multimers, which is similar to the higher order organization observed previously for higher plant cpDNA. The relative amounts of the four multimeric cpDNA forms were estimated to be about $1,1 / 2,1 / 4$, and $1 / 8$ based on molecular hybridization analysis. Phylogenetic analyses based on a concatenated alignment of chloroplast protein sequences suggested that $B$. hypnoides is sister to all Chlorophyceae and this placement received moderate support.

Conclusion: All of the results suggest that the autonomy of the chloroplasts of B. hypnoides has little to do with the size and gene content of the cpDNA, and the IR-lacking structure of the chloroplasts indirectly demonstrated that the multimeric molecules might result from the random cleavage and fusion of replication intermediates instead of recombinational events.
\end{abstract}

Citation: Lü F, Xü W, Tian C, Wang G, Niu J, et al. (2011) The Bryopsis hypnoides Plastid Genome: Multimeric Forms and Complete Nucleotide Sequence. PLoS ONE 6(2): e14663. doi:10.1371/journal.pone.0014663

Editor: Shin-Han Shiu, Michigan State University, United States of America

Received May 18, 2010; Accepted January 11, 2011; Published February 14, 2011

Copyright: @ 2011 Lü et al. This is an open-access article distributed under the terms of the Creative Commons Attribution License, which permits unrestricted use, distribution, and reproduction in any medium, provided the original author and source are credited.

Funding: The work was supported by the National Natural Science Foundation of China $(30970302,40806063$, and 30830015). The funders had no role in study design, data collection and analysis, decision to publish, or preparation of the manuscript.

Competing Interests: The authors have declared that no competing interests exist.

*E-mail: gcwang@qdio.ac.cn

9 These authors contributed equally to this work.

\section{Introduction}

The chloroplast of plants is thought to be descended from an originally free-living cyanobacterium; most of the genes in the genome of the cyanobacterium were transferred to the nucleus of the host cell during the evolutionary transformation of the endosymbiont into the chloroplast [1,2]. Nevertheless, the chloroplast retained its own genome, which performs some essential metabolic and biosynthetic pathways, such as photosynthesis and amino acid biosynthesis [1].

Chloroplast genomes (cpDNA) were the first plant genomes to be characterized because of their small size, limited number of repeated elements, and abundance of foliar tissues. At present, complete chloroplast genome sequences have been obtained from virtually all of the major higher plant and algal lineages. Comparative analyses of those complete cpDNA sequences not only highlight considerable differences at the organizational level, but also offer clarification of the evolutionary relationships among the main groups of algae and higher plants [3-6].
Compared with higher plants, algal chloroplast genomes, especially those of the green algae, exhibit numerous extreme features [7]. The cpDNA of Helicosporidium sp. [8], a parasitic, nonphotosynthetic green alga, is only $37.5 \mathrm{~kb}$ in size, which is the smallest among the cpDNAs characterized, and it lacks all genes for proteins that function in photosynthesis. The cpDNA size of the siphonous alga Acetabularia sp. is more than $2000 \mathrm{~kb}$, which is the largest known cpDNA of photosynthetic organisms $[1,9]$.

The antecedents of higher plants are thought to lie within the green algal lineage $[10,11]$, so algal plastid genomics offer useful experimental guides for the higher plants. In the past few years, studies of the algal chloroplast genome have been increasing. To date, 14 complete chloroplast genomes have been sequenced for representatives of the chlorophyte lineage: the prasinophytes Nephroselmis olivacea [12], Ostreococcus tauri [13], Pyramimonas parkeae [14], Pycnococcus provasolii [14], and Monomastix sp. OKE-1 [14]; the trebouxiophytes Chlorella vulgaris [15] and Leptosira terrestris [16]; the ulvophytes Pseudendoclonium akinetum [5], Oltmannsiellopsis viridis [17], and Helicosporidium sp. [8]; and the chlorophytes Chlamydomonas 
reinhardtii [18] Scenedesmus obliquus [19], Stigeoclonium helveticum [20], and Oedogonium cardiacum [21]. Because the divergence order of these lineages has remained contentious, more sequence data and data from additional taxa are necessary.

In addition to cpDNA sequencing, many studies now are focused on the organization of cpDNA with other elements, such as subgenomic minicircular, plasmid-like molecules [22] and the cpDNA conformation observation [23-27]. Using electron microscopy, Kolodner and Tewari [23] found that instead of only monomers, some dimers of cpDNA existed in plant cells. Deng et al. [24] reported that cpDNA can exist in trimer and tetramer form. Using in-gel procedures, including pulsed-field gel electrophoresis (PFGE), restriction fragment mapping, and fluorescence microscopy, Oldenburg and Bendich [28] found that most of the cpDNA from maize seedlings was in linear or complex branched forms rather than in circles. Multimeric forms of cpDNA also have been found in brassicas using field-inversion gel electrophoresis (FIGE) [25] and in tobacco using fluorescence hybridization in situ (FISH) [26]. In contrast, algal cpDNAs, like their higher plant counterparts, have circular restriction maps, and higher order organization (such as multimeric or anomalous forms) has not been identified in algal cpDNAs to date [7].

Bryopsis sp., which is a siphonous green alga, is a unicellular coenocytic giant cell. The total contents of the multinucleate cell can be squeezed out, leaving only the cell membranes and walls $[29,30]$. The extruded protoplasm without a cell membrane maintains sufficient viability to regenerate into a mature individual [29]. The regenerated individual can grow up to $58 \mathrm{~cm}$, which is three times longer than the wild thalli [30], suggesting that regenerated alga have an advantage over wild individuals in terms of growth. Furthermore, the Bryopsis chloroplast is the largest organelle in the cell [31] and is thought to play an important role in the protoplast regeneration process [30], thus we inferred that its cpDNA may be special regarding the genome size and coding gene compared with other algae. However, previous studies of
Bryopsis almost always have been focused on morphology and mechanisms of regeneration, and the chloroplasts, especially the cpDNAs, have received little attention.

Here we describe the complete sequence of the B. hypnoides chloroplast genome and present chloroplast phylogenies based on the genomic data currently available for higher plants and algae. Additionally, we report for the first time the presence of multimeric forms of cpDNA from B. hypnoides, a phenomenon that previously was known only for higher plant cpDNAs.

\section{Results}

\section{Growth of the germinated aggregation of protoplasts of} B. hypnoides

The protoplasm extruded from wild $B$. hypnoides immediately aggregated into numerous balls and fine strands when they were mixed with natural seawater (Figure 1A). The aggregations were covered with gelatinous envelopes within $3 \mathrm{~min}$ (Figure 1B). Some of the aggregations germinated after 24 hours (Figure 1C-E), and the germinated aggregations then developed into mature individuals (Figure $1 \mathrm{~F}$ ). As in wild $B$. hypnoides, the mature regenerated alga could also develop into the rhizoid, which was used as an anchor, and the thallus.

\section{Dimensions of chloroplasts in the $B$. hypnoides thallus}

The size of chloroplasts in the B. hypnoides thallus varied from 3 to $16 \mu \mathrm{m}$, but most were $8-12 \mu \mathrm{m}$ in length (Figure 2A), suggesting that the size diversity of the chloroplasts existed in the B. hypnoides thallus. This result was confirmed by the results of sucrose density gradient centrifugation (Figure 2B), in which five clear discrete green bands appeared in the centrifugation tubes. Then all the bands were recovered separately and observed under the light microscope. We found that all the five bands were intact chloroplasts except for a few cell debris; the chloroplasts in the five bands were of different sizes, demonstrating the presence of five kinds of chloroplasts. When
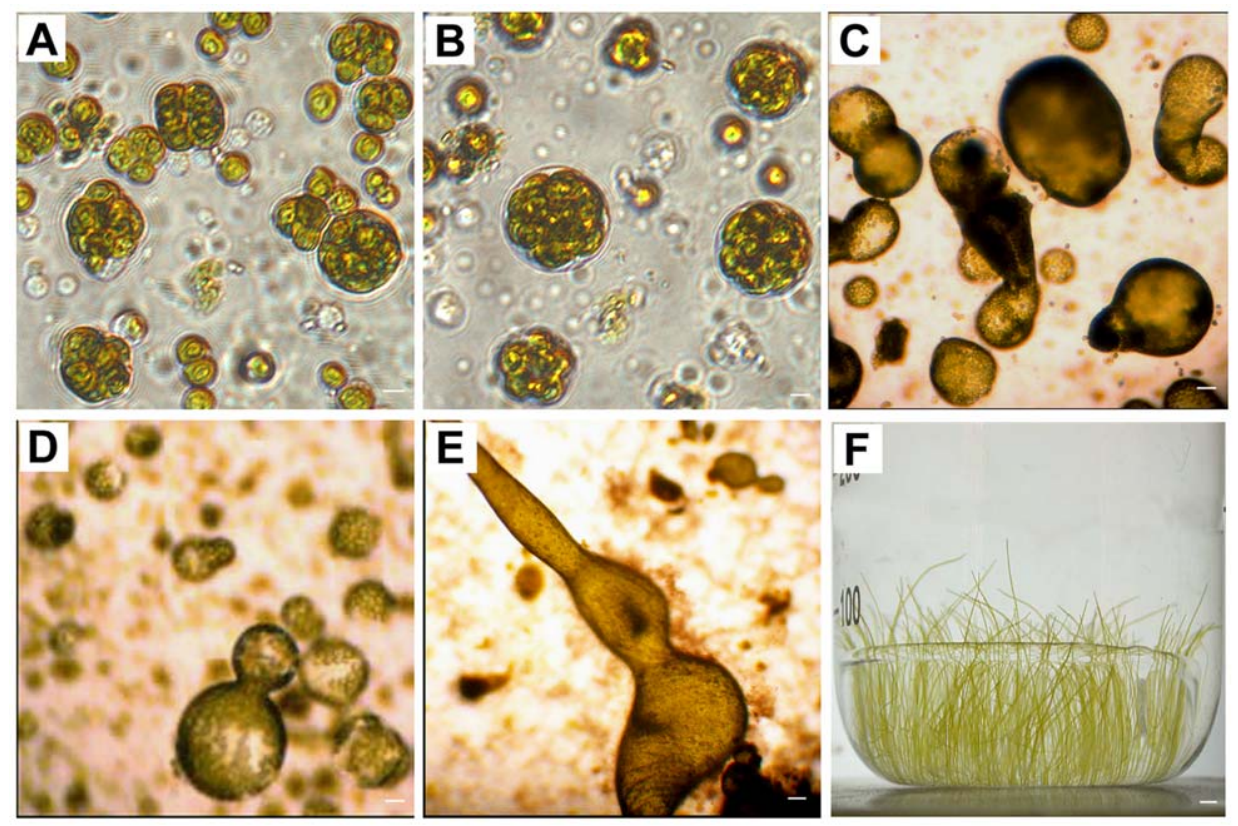

Figure 1. Formation and germination of protoplasts from B. hypnoides. A: formation of aggregation of protoplasts within 1 min; B: formation of a gelatinous envelope within $3 \mathrm{~min}$; C-E: germination of the aggregation of $B$. hypnoides protoplasts; F: the germinated aggregation was developed into a mature individual. Bars, $10 \mu \mathrm{m}(\mathrm{A}-\mathrm{E}), 1 \mathrm{~cm}(\mathrm{~F})$.

doi:10.1371/journal.pone.0014663.g001 
A

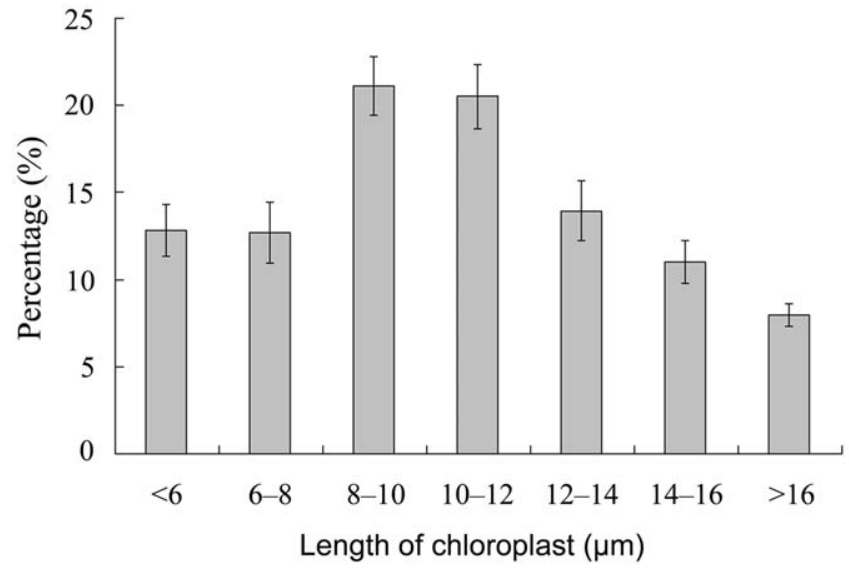

B

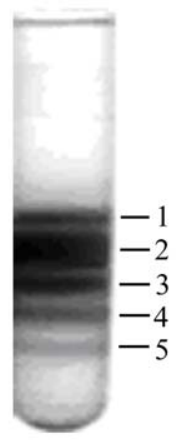

Figure 2. Dimensions of chloroplasts in the $B$. hypnoides thallus. (A) The size distribution of chloroplasts in Bryopsis hypnoides thallus as inferred by optical microscope (ZEISS HBO 50, Germany). Ten fields of vision $(\times 200)$ were selected randomly and all of the chloroplasts with different sizes were determined with an eyepiece micrometer. (B) The chloroplasts separated by sucrose density gradient centrifugation from the wild $B$. hypnoides. Numbers indicate the five discrete bands. doi:10.1371/journal.pone.0014663.g002

cultured under the same conditions, both the wild and the regenerated algal thallus displayed the same results.

\section{Structure and gene organization of the B. hypnoides chloroplast genome}

The B. hypnoides cpDNA sequence assembles into a circle of 153,429 bp; Figure 3 illustrates its gene map. Overall, the GC content of the cpDNA is $33.1 \%$, which is comparable with that of Chlamydomonas (34.5\%), Chlorella (31.6\%), Pseudendoclonium (31.5\%), and Pyramimonas (34.7\%). Like its C. sertularoides and C. fragile homologs, the chloroplast genome of $B$. hypnoides does not contain the inverted repeat that is commonly found in many chloroplast genomes. A total of 111 functional genes, including 69 potential protein-coding genes, 5 ribosomal RNA genes, and 37 tRNA genes, were identified (Table 1). In addition, 29 open reading frames (ORFs) were identified with a threshold of $300 \mathrm{bp}$. All genes are present in a single copy, and this gene content is typical for chlorophyte cpDNAs. The sequence of $B$. hypnoides was most similar to that of $C$. vulgaris when compared with other completely sequenced chlorophyte cpDNAs. Table 2 compares the gene content of B. hypnoides cpDNA with that of other Ulvophyceae, Trebouxiophyceae, and Chlorophyceae (UTC) algal cpDNAs that have been completely sequenced to date. A common set of 84 genes is shared by these genomes. Relative to ulvophytes $(O$. viridis and $P$. akinetum), seven protein genes (chlI, minD, psaI, psaM, rpl19, ycf1, and $y c f 20$ ) are absent from $B$. hypnoides cpDNA. Two genes, cys $A$ and cys $T$, that encode sulfate transport proteins are absent in the ulvophytes $O$. viridis and $P$. akinetum but are present in the trebouxiophytes $C$. vulgaris and $L$. terrestris and in our B. hypnoides cpDNA.

In terms of gene organization, many derived gene clusters are shared specifically between $B$. hypnoides, $C$. vulgaris, $O$. viridis, and $P$. akinetum cpDNAs (i.e., rpl16-rpl14-rpl5-rps8-infA-rpl36-rps11-rpoA, rps2-atpI-atpH-atpF-atpA, psbE-psbF-psbL-psbf, and ccsA-chlL-chlN (not in $P$. akinetum)), as are gene pairs (i.e., atpB-atpE, petB-petD, rpl2-rps19, rps12-rps7, psbD-psbC, rpoC1-rpoC2, rps19-rps3, rps9-rpl12, rps2-atpI, rpl20-rps18, psbK-ycf12, and psaA-psaB (not in P. akinetum)) as well as two ancestral gene pairs ( $p s b B-p s b T$ and $r p l 23-r p l 2)$. The gene pairs rps3-rpl16, rpoB-rpoC1, and tufA-rpl19 and the petA-petLpet $G$ cluster are missing from our B. hypnoides cpDNA.

Eleven introns in the $B$. hypnoides chloroplast are distributed among ten genes, among which rrs exhibits two introns and atpA,
psaA, psbB, rbcL, rpl2, rpl5, rpl23, trnL-UAA and $y c f 3$ each contain one intron. These introns vary from 348 to $2466 \mathrm{bp}$ in size. According to their secondary structures, five introns belong to the group I family [32], and three of these carry an internal ORF encoding a putative LAGLIDADG homing endonuclease. The intron of rpl2 is commonly present in the chloroplast genomes of land plants, however it not found in the completely sequenced chlorophyte cpDNAs. The introns of rpl5 and rpl23 in Bryopsis are the first found in the known chloroplast genomes of Viridiplantae, and blast searches of these two intron sequences against the GenBank database failed to detect any homologous introns in other organisms.

\section{PFGE analysis of cpDNA}

Figure 4A shows the results of PFGE analysis of cpDNAs of the wild $B$. hypnoides. In the cpDNAs from the different types of chloroplasts purified by sucrose density gradient centrifugation, at least four clear bands can be seen in every lane, each corresponding to a type of $B$. hypnoides chloroplast. The southern hybridization with labeled probes of the $r b c L$ gene showed all the four bands were positive (Figure 5), suggesting that the four bands represented all of the cpDNAs from B. hypnoides. The four bands were located at $150 \mathrm{~kb}, 300 \mathrm{~kb}, 450 \mathrm{~kb}$, and $600 \mathrm{~kb}$, all of which were in multiple relations. The relative amounts of the four bands in PFGE, which corresponded to monomers, dimers, trimers, and tetramers of the $B$. hypnoides cpDNAs, were estimated to be about $1,1 / 2,1 / 4$, and $1 / 8$ based on molecular hybridization.

Figure 4B shows the results of PFGE analysis of cpDNAs from the regenerated $B$. hypnoides. These results are almost the same as those shown in Figure 4A, which confirms that the cpDNAs from the regenerated individual are similar to those of the wild alga.

\section{Phylogenetic position of $B$. hypnoides chloroplasts}

To elucidate the overall position of $B$. hypnoides in the plastid phylogeny of algae/land plants, a global analysis was performed using a subset of 31 taxa (see supplemental data) and 14,160 aligned characters. Thirty-one organisms were included as representatives of algae and higher plants and included the green lineage (streptophyte and chlorophyte lineage) and the non-green lineage (red and chromist lineage). The best tree identified two distinct lineages: the green lineage and the non-green lineage. 


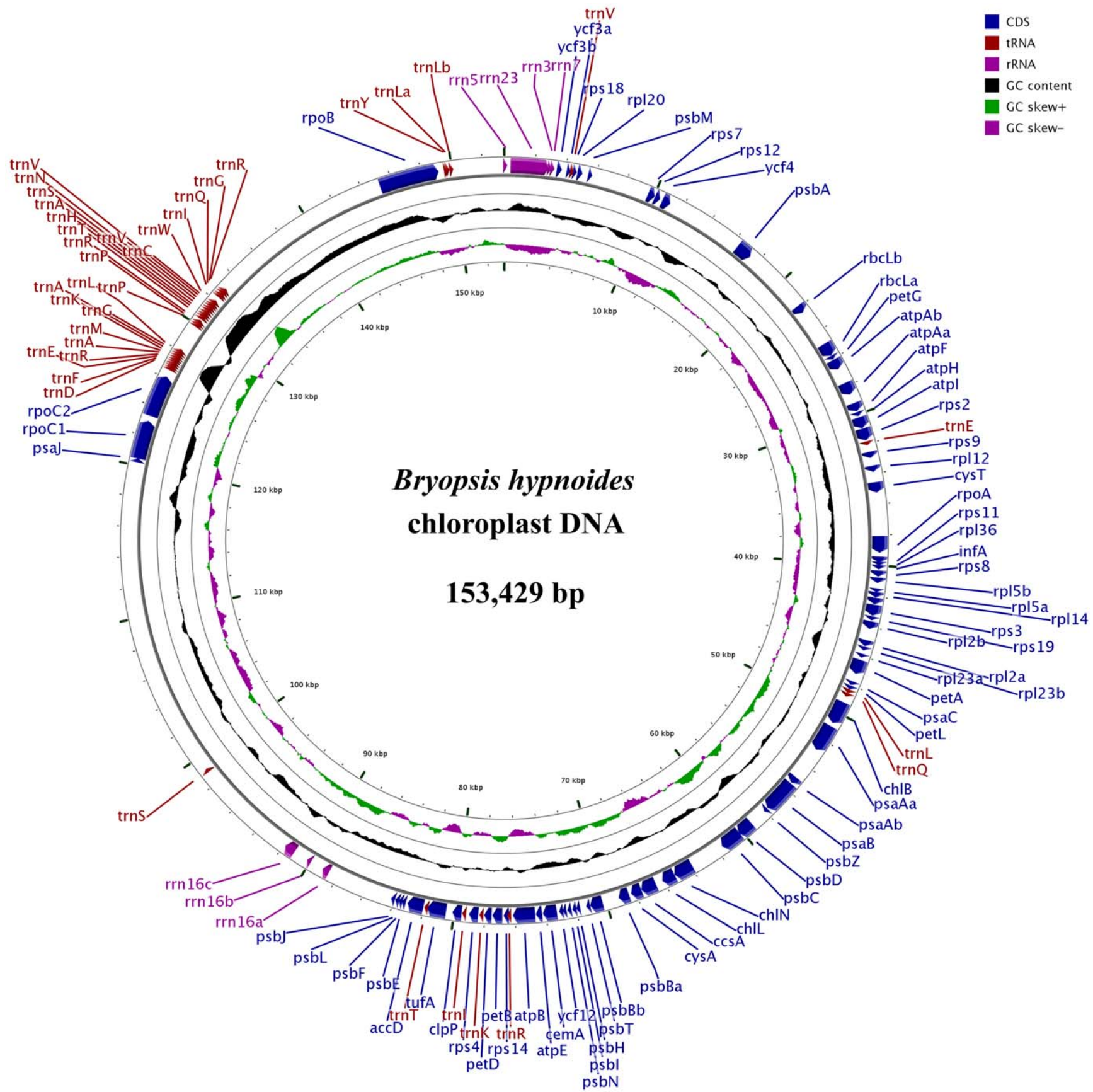

Figure 3. Gene map of the $B$. hypnoides chloroplast genome. Position 0 is in the $12 o^{\prime}$ clock position. The CDs of the genes are shown in blue, tRNA genes are indicated as red, and genes of rRNA are shown in violet. doi:10.1371/journal.pone.0014663.g003

Moreover, the chlorophytes and streptophytes formed two distinct green lineages (Figure 5). Unexpectedly, the trees inferred with ML and MP methods both identified a clade uniting B. hypnoides and four complete sequenced members of the Chlorophyceae, this clade received $90 \%$ and $62 \%$ bootstrap value in MP and ML analyses, respectively. For other chlorophytes, $\mathcal{N}$. olivacea represents the first branch of the Chlorophyta, which is also reported in recent phylogenetic analyses $[6,12]$, but the branching order of the other four Prasinophyceae $(O$. tauri, $P$. parkeae, $P$. provasolii and Monomastix sp.) showed the different topology in the ML and MP analyses. In ML tree, $P$. provasolii is sister to all other UTC algae (bootstrap 51\%); in the MP topology, it forms a moderately supported clade with $O$. tauri, Monomastix sp. and P. parkeae. For the UTC algae, the topological differences are also seen in the $C$. vulgaris clade, which was clustered with two Ulvophyceae $(O$. viridis and $P$. akinetum $)$ in the MP tree, whereas in the ML tree, it located at the basal position within the UTC algae.

The relationships observed for the non-green algae and streptophytes taxa in the phylogeny are congruent with recently published phylogenies based on whole chloroplast genome sequences [6,33]. Within the Streptophyta, the clade uniting Chlorokybus and Mesostigma was placed basally and received strong bootstrap support. The other 
Table 1. Genes contained in B. hypnoides chloroplast DNA.

\begin{tabular}{|c|c|}
\hline Gene products & Genes \\
\hline Photosystem I & $p s a A^{b}, B, C, J$ \\
\hline Photosystem II & $p s b \mathrm{~A}, \mathrm{~B}^{\mathrm{a}}, \mathrm{C}, \mathrm{D}, \mathrm{E}, \mathrm{F}, \mathrm{H}, \mathrm{I}, \mathrm{J}, \mathrm{K}, \mathrm{L}, \mathrm{M}, \mathrm{N}, \mathrm{T}, \mathrm{Z}$ \\
\hline Cytochrome b6/f & petA, B, D, G, L \\
\hline ATP synthase & $\operatorname{atpA^{a},B,E,F,H,~I~}$ \\
\hline Chlorophyll biosynthesis & $c h / B, L, N$ \\
\hline Rubisco & $r b c L^{\mathrm{b}}$ \\
\hline Large subunit ribosomal proteins & $r p / 2^{b}, 5^{b}, 12,14,16,20,23^{b}, 32,36$ \\
\hline Small subunit ribosomal proteins & $r p s 2,3,4,7,8,9,11,12,14,18,19$ \\
\hline RNA polymerase & rpoA, B, C1, C2 \\
\hline Translation & infA, tufA \\
\hline Other proteins & accD, ccsA, cemA, clpP, cysA, cys $\mathrm{T}$ \\
\hline Proteins of unknown function & $y c f 3^{b}, 4,12$ \\
\hline Ribosomal RNAs & $r r n 23,16^{\text {aa }}, 7,5,3$ \\
\hline Transfer RNAs & $\begin{array}{l}\operatorname{trnA}(\mathrm{UGC}), A(\mathrm{CGC}), A(\mathrm{AGC}), C(\mathrm{GCA}), D(\mathrm{GUC}), E(\mathrm{UUC}), E(\mathrm{CUC}), F(\mathrm{GAA}), G(\mathrm{UCC}), \mathrm{G}(\mathrm{GCC}), H(\mathrm{GUG}), I(\mathrm{AAU}), I(\mathrm{GAU}) \text {, } \\
K(\mathrm{CUU}), K(\mathrm{UUU}), L(\mathrm{CAA}), L(\mathrm{UAA}))^{2}, L(\mathrm{UAG}), M(\mathrm{CAU}), N(\mathrm{GUU}), P(\mathrm{UGG}), P(\mathrm{AGG}), Q(\mathrm{CUG}), Q(\mathrm{UUG}), R(\mathrm{ACG}), R(\mathrm{CCU}), \\
R(\mathrm{UCG}), R(\mathrm{UCU}), S(\mathrm{GCU}), S(\mathrm{UGA}), T(\mathrm{AGU}), T(\mathrm{UGU}), V(\mathrm{AAC}), V(\mathrm{CAC}), V(\mathrm{UAC}), W(\mathrm{CCA}), Y(\mathrm{GUA})\end{array}$ \\
\hline
\end{tabular}

${ }^{\mathrm{a} G e n e s}$ containing one- and two- group I introns.

${ }^{\mathrm{b}}$ Genes containing group II introns.

doi:10.1371/journal.pone.0014663.t001

four Charophyceae were clustered with two higher plants $(\mathcal{N}$. tabacum and $M$. polymorpha). In terms of the non-green lineage examined in this study, $P$. purpurea and $G$. tenuistipitate var. liui formed a strongly supported lineage that is sister to the clade uniting the $G$. theta, $R$. salina, $O$. sinensis and $E$. huxleyi. Two other red algae, $C$. merolae and $C$. caldarium, robustly clustered in a separate clade.

\section{Discussion}

\section{The autonomy of the $B$. hypnoides chloroplast}

Our previous studies showed that the chloroplasts of B. hypnoides had strong autonomy for the following reasons: (1) The chloroplasts in $B$. hypnoides had greater vitality than other organelles under unfavorable conditions [34]; (2) chloroplasts purified by sucrose density gradient centrifugation can aggregate into spheres, although they cannot develop into mature individuals [35]; and (3) The chloroplasts from siphonous algae possess great vitality and can maintain activity in other cells or other body cavities. For example, a symbiotic association exists between siphonaceous green algae (Acetabularia, Bryopsis, Caulerpa, and Codium) plastids and some marine sea slug species that are highly specialized herbivores that feed on siphonalean algae by puncturing the cells and sucking out the contents. The chloroplasts of siphonous algae are not always digested and can lodge in the body of the animal and conduct photosynthesis for at least 3 months [36-41]. Moreover, genes supporting photosynthesis have been acquired by the host animal via horizontal gene transfer, and the encoded proteins are retargeted to the chloroplast [42]. In summary, compared with chloroplasts of other algae and higher plants, B. hypnoides chloroplasts have great vitality and independence. Because of these extraordinary traits, we conducted research both on the genome sequence and the conformation of the cpDNA.

\section{Distinctive features of the $B$. hypnoides chloroplast genome}

The genome size, arrangement, and IR-lacking structure of the chloroplast genome of $B$. hypnoides more closely resemble that of $C$. vulgaris cpDNA [15] than its O. viridis [17] and P. akinetum [5] homologs. In addition to the 84 conserved genes that exist in all of the completely sequenced UTC algal cpDNAs, B. hypnoides shares an additional 14 genes with $C$. vulgaris cpDNA, compared to 12 and 10 genes with $O$. viridis and $P$. akinetum, respectively (Table 2).

Among the chlorophycean algal plastids investigated to date, the inverted repeat is lost in the prasinophytes (Monomastix and Pycnococcus [14]); trebouxiophytes (Chlorella [15], Helicosporidium [8], and Leptosira [16]); ulvophytes (Caulerpa [43] and Codium [44]); and the chlorophyte Stigeoclonium [20], suggesting that this ancestral character has been independently lost in those lineages. Furthermore, considering the atypical quadripartite structure of Oltmannsiellopsis and Pseudendoclonium cpDNAs identified previously, the chloroplast genome of the Ulvophyceae likely has evolved under relaxed constraints [5].

The most notable feature of the B. hypnoides chloroplast genome is that the rRNA locus consists of five genes: $r m 23, \operatorname{rr} 16, r m 7, r m 5$, and rm3. The same situation can be found only in C. reinhardtii cpDNA [18], as genes $r m 7$ and $r m 3$ are absent from all other completely sequenced chlorophyte cpDNAs. Similar to $C$. reinhardti, the rRNA gene cluster of $B$. hypnoides is arranged in the order $r m 16$ - $r m 5$ - $r m 23-r m 3-r m 7$; however, the typical rRNA operon in B. hypnoides has been broken in half and the SSU and LSU genes are distributed at opposite ends of the gene map circle, as is found in the ulvophytes C. sertularoides [43] and C. fragile [44]; this might be an outcome of the loss of the inverted repeat.

Another surprising feature of the $B$. hypnoides chloroplast gene repertoire is the presence of 10 unusual tRNA genes that have not been found in other completely sequenced chlorophyte cpDNAs. Five of them (trnA-AGC, $t m E-\mathrm{CUC}$, $t m I-\mathrm{AAU}, \operatorname{tr} V$-CAC, and $t m V$ AAC) correspond to those identified in some embryophyte cpDNAs, whereas the other five $(t m A$-CGC, $t m K$-CUU, $t m P-A G G, t m Q-\mathrm{CUG}$, and $\operatorname{trn}$ T-AGU) have been found previously only in some bacterial genomes. These unusual tRNA genes may not be essential for plastid function in green algae or may not be functional genes; they also might be involved in the special physiological functions of $B$. hypnoides.

Wolfe et al. [45] reported that the $\mathrm{cp}$ genome of Epifagus virginiana, a plant with non-photosynthetic chloroplasts, encodes 
Table 2. Gene Content in B. hypnoides and Other UTC Algal cpDNAs.

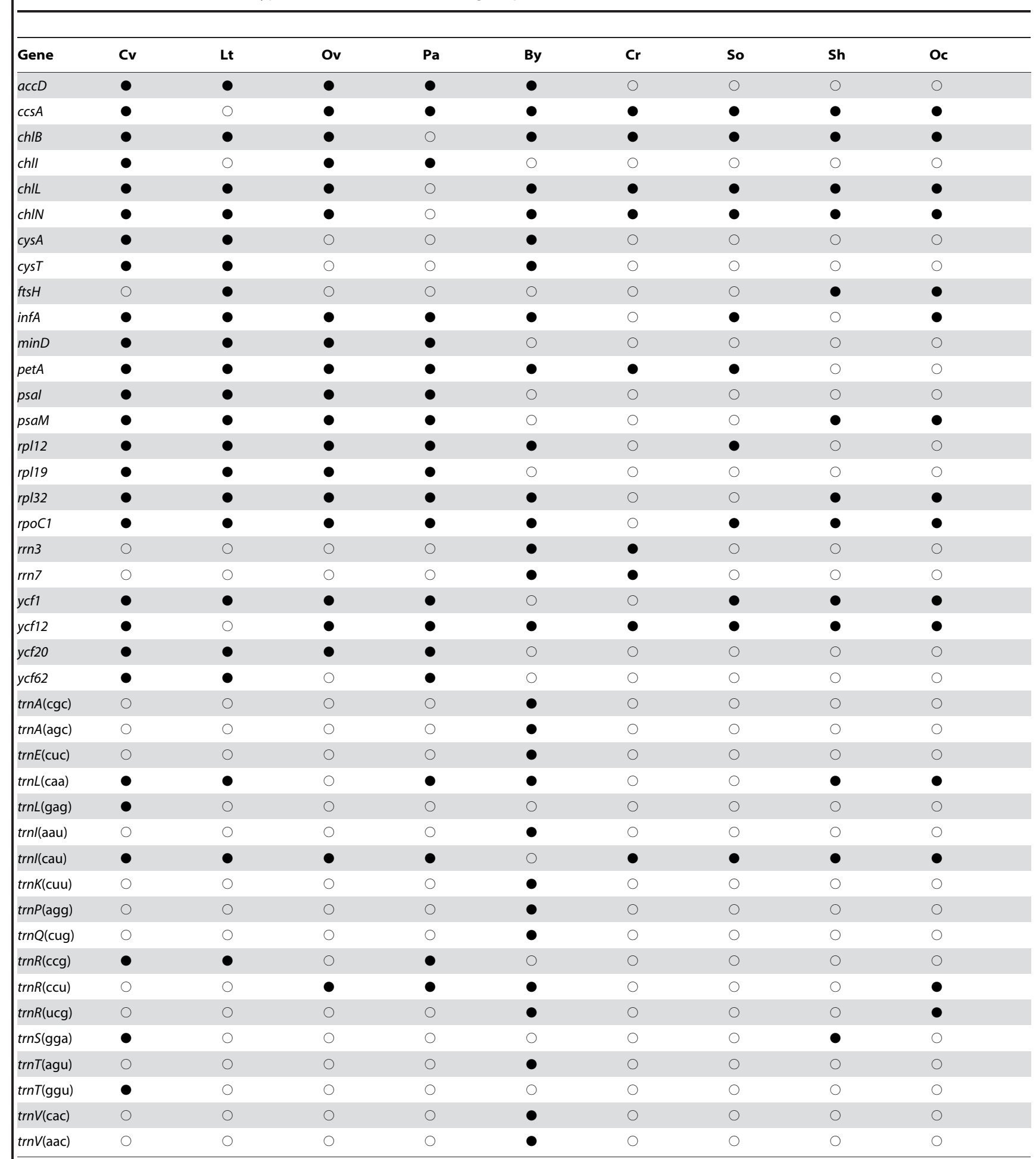

Cv: Chlorella vulgaris, Lt: Leptosira terrestris, Ov: Oltmannsiellopsis viridis, Pa: Pseudendoclonium akinetum, By: Bryopsis hypnoide, Cr: Chlamydomonas reinhardtii,

So: Scenedesmus obliquus, Sh: Stigeoclonium helveticum, Oc: Oedogonium cardiacum. A filled/open circle denotes the presence/absence of a gene. Only the genes that

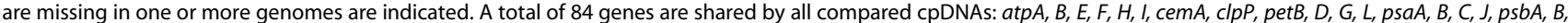
$C, D, E, F, H, I, J, K, L, M, N, T, Z, r b c L, r p l 2,5,14,16,20,23,36, r p o A, B, C 2, r p s 2,3,4,7,8,9,11,12,14,18,19, r r f, r r l, r r s, t u f A, y c f 3,4, \operatorname{trn} A(\mathrm{ugc}), C(\mathrm{gca}), D$ (guc), E(uuc), F(gaa), $G(\mathrm{gcc}), G(\mathrm{ucc}), H(\mathrm{gug}), I(\mathrm{gau}), K(\mathrm{uuu}), L(\mathrm{uaa}), L(\mathrm{uag}), M e(\mathrm{cau}), M f(\mathrm{cau}), N(\mathrm{guu}), P(\mathrm{ugg}), Q(\mathrm{uug}), R(\mathrm{acg}), R(\mathrm{ucu}), S(\mathrm{gcu}), S(\mathrm{uga}), T(\mathrm{ugu}), V(\mathrm{uac}), W(\mathrm{cca}), Y(\mathrm{gua})$.

doi:10.1371/journal.pone.0014663.t002

only 25 proteins because the photosynthetic machinery and the corresponding genes are not needed. Glöckner et al. [46] identified several genes unique to the cp genome of $C$. caldarium that correlate to its special environmental conditions. Thus, it seems that loss or gain of function is accompanied by changes of genes in the cp genome. Herein we originally presumed that the size and gene 


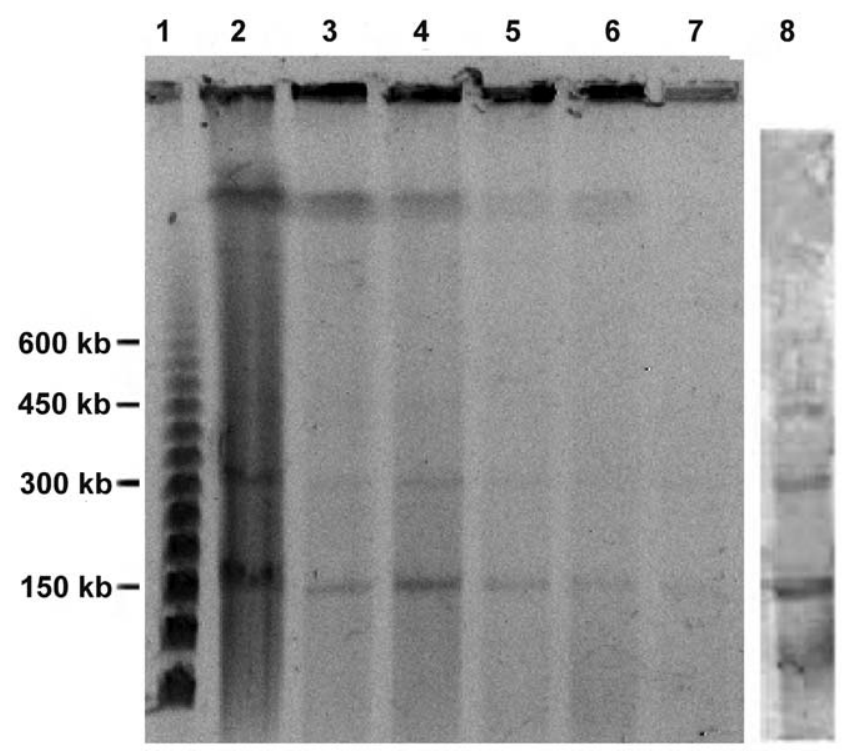

Figure 4. PFGE showing multimeric forms of chloroplasts from the wild (A) and the regenerated (B) B. hypnoides. (A) lane 1: molecular standard marker; lane 2: cpDNAs from crude chloroplasts of $B$. hypnoides without purification by sucrose density gradient centrifugation; lanes 3-7: cpDNAs from different chloroplasts separated by sucrose density gradient centrifugation; lane 8: the cpDNA hybridized with the labeled probe of $r b c L$ gene. (B) lane 1: molecular standard marker; lanes 2-6: cpDNAs from different chloroplasts separated by sucrose density gradient centrifugation (corresponding to the bands 1-5 in Fig. 3); lane 7: the cpDNA hybridized with the labeled probe of $r b c L$ gene.

doi:10.1371/journal.pone.0014663.g004

content of the chloroplast genome of B. hypnoides should be extraordinary in order to support its autonomy. However, we found that $B$. hypnoides possesses the usual chloroplast genome of $153 \mathrm{kbp}$ and that the gene repertoire is typical for chlorophyte cpDNAs. Thus, the autonomy of chloroplasts of B. hypnoides seems to have little to do with the size and gene content of the cpDNA.

\section{The multimeric forms conformation of $B$. hypnoides cpDNA}

Figure 4 shows that the cpDNA of $B$. hypnoides has multimeric forms, including at least monomers, dimers, trimers, and tetramers, and these are similar to the multimeric cpDNA forms of higher plants, such as Arabidopsis, tobacco, and peas [24,26,47]. The five different sizes of $B$. hypnoides chloroplasts showed the same cpDNA characteristics in multimeric forms, suggesting that the relative amounts of the different forms of $B$. hypnoides cpDNA had no relationship to chloroplast dimension.

Green alga is thought to have been the progenitor of higher plants [10-12]; B. hypnoides is a green alga thus, its cpDNA conformation may be similar to that of higher plants. However, a PFGE study of the $C$. reinhardtii chloroplast genome did not reveal the higher order organization that was observed previously for higher plant cpDNAs [18]. Our phylogenetic tree revealed that B. hypnoides is located in the same clade as $C$. reinhardtii (Figure 5), whereas their cpDNA conformations were quite different. This finding indicates that the cpDNA of green algae is structurally plastic.

Lilly et al. [26] proposed that the formation of higher order multimeric molecules may result from recombinational events or the random cleavage and fusion of replication intermediates. Recombinational events correlate to the presence of IRs, as revealed in both Arabidopsis and tobacco [26,48]. Recombination between IRs that occurs on two separate monomers results in a dimer [49]; subsequent recombination events between molecules presumably produce multimers. However, our study demonstrated that multimeric forms of cpDNA also exist in the IR-lacking chloroplast genome, which suggests that the higher order organization of the chloroplast genome maybe less related to the presence of IRs than was previously thought. Our results indirectly support the alternative explanation that multimeric molecules were produced by the random cleavage and fusion of replication intermediates. However, this explanation requires confirmation further.

\section{Similar conformation of cpDNA between wild and regenerated $B$. hypnoides}

Our previous studies showed that the regenerated alga had an advantage over the wild individual in terms of growth and that biochemical compositions differed between the wild and the regenerated alga [30,34]. The regenerated alga can grow up to $58 \mathrm{~cm}$ in length, which is three times longer than the wild form [30]. Wang and Tseng [34] reported that when the regenerated alga was on the decline, the organelles aggregated in the thallus and then moved to the outside; next, one organelle aggregation located outside of the thallus germinated and developed into a mature alga. From this, we inferred that the DNA in the organelles of the regenerated alga, especially the cpDNAs, underwent changes during organelle aggregation and later development into a mature individual. The cpDNAs from the regenerated $B$. hypnoides were similar in size and conformation to the cpDNA of the wild alga (Figure 4), and both exhibited monomeric, dimeric, trimeric, and tetrameric forms of cpDNAs. Thus, the differences between the wild alga and the regenerated individual probably result from gene expression rather than alteration of the genome, especially the cpDNAs.

\section{Evolution of the chlorophycean chloroplast genome}

The basal position of the Prasinophyceae in the Chlorophyta is well established, but the branching order of the Ulvophyceae, Trebouxiophyceae, and Chlorophyceae remains unresolved $[5,51]$. There are two hypotheses concerning the divergence order of the UTC lineages: 1) phylogenetic inferences from cpDNAencoded proteins and genes favor the hypothesis that the Ulvophyceae is a sister to the Trebouxiophyceae [5]; and 2) chloroplast phylogenies inferred from gene order [5] and mitochondrial phylogenies inferred from proteins or genes [51] suggest that the Ulvophyceae share a sister relationship with the Chlorophyceae. Our phylogenetic analyses of 42 chloroplast proteins revealed that the Ulvophyceae clade $\mathrm{I}(O$. viridis and $P$. akinetum) is a sister to the Trebouxiophyceae I (C. vulgaris). However, the $B$. hypnoides (Ulvophyceae II) chloroplast genome is closely related to the Chlorophyceae. Although the B. hypnoides chloroplast genome shares similarities with its $O$. viridis and $P$. akinetum counterparts in terms of gene order, its IR-lacking structure and gene content are quite different; we therefore inferred that Ulvophyceae was non-monophyletic group, $B$. hypnoides is located in the different phylogenetic lineage with $O$. viridis and $P$. akinetum. Moreover, our phylogenetic analyses favor the premise that the Trebouxiophyceae and Prasinophyceae were also non-monophyletic groups, thus it was difficult to state a precise taxonomic relationship among the UTC lineages in this study. These different phylogenetic results may be caused by the insufficient taxon sampling. So studies on additional chloroplast genome data, especially from the UTC algae, will be very useful for determining the phylogenetic relationships among the major lineages of Chlorophyta. 


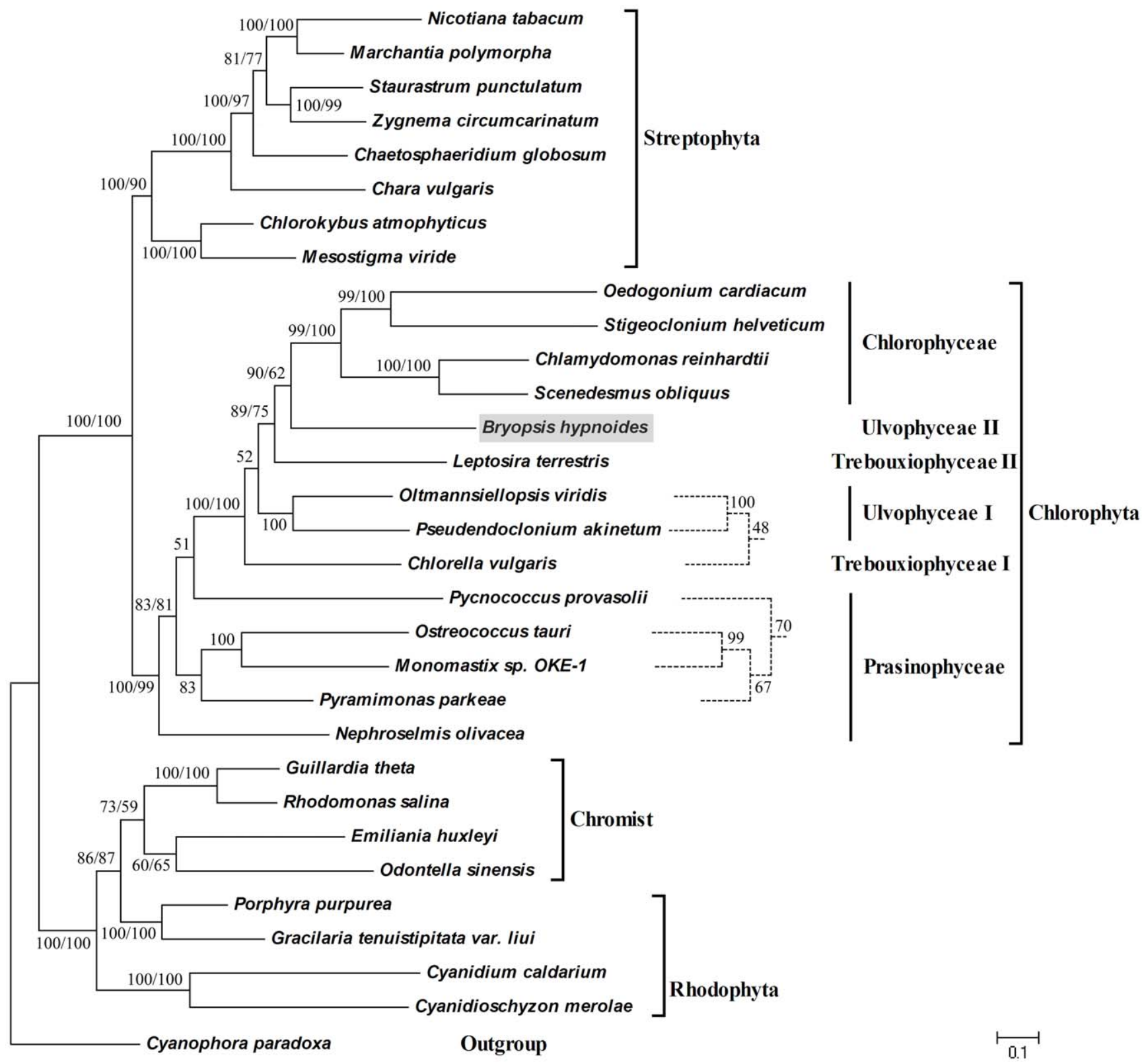

Figure 5. Phylogenetic position of $B$. hypnoides as inferred by ML analyses of 42 cpDNA-encoded proteins. Family-level affinities are shown on the right of the diagram. Cyanophora paradoxa were used as outgroup. Numbers in each branch indicated maximum-likelihood (ML) / maximum parsimony (MP) bootstrap values; and the dashed lines indicated the MP topologies which were different from the ML tree. doi:10.1371/journal.pone.0014663.g005

\section{Materials and Methods}

\section{Materials}

Bryopsis hypnoides Lamouroux was collected from the intertidal zone of Zhanqiao Pier, Qingdao, China $\left(36^{\circ} 3^{\prime} \mathrm{N}, 120^{\circ} 19^{\prime} \mathrm{E}\right)$. The fresh algae, which were rinsed with plenty of autoclaved seawater and brushed with a soft brush to remove the surface microbial and epiphytic organisms, were cultured in autoclaved sea water under irradiance of $25 \mu \mathrm{mol} \mathrm{m}{ }^{-2} \cdot \mathrm{s}^{-1}$ with a $16 \mathrm{~h}$ light: $8 \mathrm{~h}$ dark regime at room temperature [30].

The aggregation of organelles in the protoplasm

Thalli of B. hypnoides were cut into small pieces and then placed in eight layers of sterilized gauze to squeeze out the protoplasm.
The extruded protoplasm was mixed with an equal volume of sterilized seawater ( $\mathrm{pH}$ 8.3) and gently rocked. The organelles in the protoplasm aggregated into spheres of different sizes, and the aggregated spheres were cultured into mature B. hypnoides (the regenerated $B$. hypnoides) under the culture conditions described above.

\section{Chloroplast and cpDNA purification}

The protoplasts squeezed from the wild $B$. hypnoides were added to double volume ice-cold extraction buffer $(400 \mathrm{mM}$ sucrose, $50 \mathrm{mM}$ Tris, $20 \mathrm{mM}$ EDTA, $0.2 \%$ BSA, $0.2 \% \beta$-mercaptoethanol, $\mathrm{pH}$ 7.8) and then filtered through four layers of cheese cloth. The filtrate was centrifuged at $800 \mathrm{~g}$ at $4^{\circ} \mathrm{C}$ for $10 \mathrm{~min}$, and the pellet was suspended in the extracted buffer. Most of the pellets 
were found to be chloroplasts under microscopic examination, so they were layered onto the sucrose density gradient from $10 \%$ to $60 \%$. The gradient was centrifuged at $150,000 \mathrm{~g}$ for $90 \mathrm{~min}$, and five clear green bands appeared in the tube after centrifugation. The bands were removed from the tube separately, and dialyzed against the rinse buffer $(400 \mathrm{mM}$ sucrose, $50 \mathrm{mM}$ Tris, $0.5 \%$, BSA $\mathrm{pH}$ 7.8) for 5 hours to remove sucrose, then were observed under the microscope.

The purified chloroplasts were washed twice with the buffer (50 mM Tris-HCl, pH 8.0, 25 mM EDTA), suspended in the lysis buffer (50 mM Tris, pH 8.0, 25 mM EDTA, 2\% SDS, $50 \mu \mathrm{g} / \mathrm{ml}$ proteinase $\mathrm{K}$ ), and incubated at $40^{\circ} \mathrm{C}$ for 3 hours with gently shaking, following by being centrifuged at $10000 \mathrm{~g}$ at $4^{\circ} \mathrm{C}$ for $15 \mathrm{~min}$. The supernatant was extracted several times with phenol/ chloroform and then precipitated with cold ethanol. Ciscl density gradient ultracentrifugation was used for further purification of the cpDNA. CsCl and Hoechst dye No. 33258 were added to the crude cpDNA, and the mixture was centrifuged at $240,000 \mathrm{~g}$ at $20^{\circ} \mathrm{C}$ for 38 hours with a Beckman Ti 80 rotor. cpDNA bands were visualized under UV illumination and then recovered. The cpDNA was precipitated and dissolved in TE buffer after both the Hoechst dye 33258 and $\mathrm{CsCl}$ were removed. The cpDNA from the regenerated $B$. hypnoides then was purified as described above.

\section{cpDNA sequencing}

The purified cpDNA was sheared by nebulization, and $1,500 \pm 3,000 \mathrm{bp}$ fragments were recovered by electroelution after agarose gel electrophoresis. These fragments were treated with T4 DNA polymerase and cloned into the SmaI site of PUC18. After transformation of electrocompetent E. coli TOP10 cells (Invitrogen, Carlsbad, CA), recombinant plasmids were isolated and nucleotide sequences were determined with the PRISM dye terminator cycle sequencing kit (Applied Biosystems, Foster City, CA) on a DNA sequencer (model 373; Applied Biosystems) using T3 and T7 primers. Sequencing data were accumulated to $10 \times$ coverage for all PGR fragments; remaining gaps were cloned by PCR. The determined sequences were accumulated, trimmed, aligned, and assembled using the Phred-Phrap (Phil Green, University of Washington, Seattle, WA, USA) and Consed programs [52]. The fully annotated B. hypnoides chloroplast genome sequence has been deposited in GenBank with accession number GQ892829.

\section{PFGE and southern blot analysis}

The PFGE assay was performed by the method described by Sambrook and Russell [53]. Brifely, the purified chloroplasts were mixed with an equal volume of low melting point agarose, which was dissolved in rinse buffer containing $20 \mathrm{mM}$ EDTA, and $90 \mu \mathrm{l}$ of the mixture was added into every pole of the mould (Bio-Rad, Richmond, Calif), then solidified at $4^{\circ} \mathrm{C}$. The solid gels were put into the lysis buffer $(0.01 \mathrm{M}$ Tris, $0.45 \mathrm{M}$ EDTA, $\mathrm{pH} 7.8,2 \%$ SLS, $10 \mu \mathrm{g} / \mathrm{ml}$ proteinase $\mathrm{K}$ ) and incubated at $50^{\circ} \mathrm{C}$ for $40 \mathrm{~h}$, during which the buffer was changed twice. The gels then were rinsed six times with TE (10 mM Tris, $1 \mathrm{mM}$ EDTA, pH 8.0) and then stored at $4^{\circ} \mathrm{C}$. Pulsed-field gel electrophoresis (PFGE) was performed on a Bio-Rad CHEF Mapper TM according to the

\section{References}

1. Martin W, Herrmann RG (1998) Gene transfer from organelles to the nucleus: how much, what happens, and why? Plant Physiol 118: 9-17.

2. Richly E, Leister D (2004) An improved prediction of chloroplast proteins reveals diversities and commonalities in the chloroplast proteomes of Arabidopsis and rice. Gene 329: 11-16.

3. Olmstead RG, Palmer JD (1994) Chloroplast DNA systematics: a review of methods and data analysis. Amer J Bot 81: 1205-1224. manufacturer's instructions (CHEF Mapper TM and CHEF Mapper XA Pulsed Field Electrophoresis Systems). After PFGE, the gel was dyed with $0.5 \mu \mathrm{g} / \mathrm{ml} \mathrm{EB}$ for $30 \mathrm{~min}$, and the result was observed by Pharmacia Biotech Imagemaster ${ }^{\circledR}$ VDS.

A DNA fragment encoding the B. hypnoides $r b c L$ gene $(1145 \mathrm{bp}$; GenBank accession no. AY566304) was prepared from genome DNA as described previously [54]. The $r b c L$ gene then was labeled according to the directions provided in the Dig High Prime DNA Labeling and Detection Starter Kit I (Roche, Germany) and used as a probe for southern blot analysis. DNA in the gel was denatured and transferred to the positively charged nylon membrane (Osmonics, Westborough, MA, USA) [53] and crosslinked under UV for 90 seconds, then hybridized with the probe following the instructions for the Roche Kit.

\section{Sequence and phylogenetic analyses of cpDNA}

Genes were identified using Blast homology searches provided by the National Center for Biotechnology Information (NCBI) server (http://www.ncbi.nlm.nih.gov/BLAST/). Protein-coding genes and positions of ORFs were determined using ORFFINDER at NCBI. tRNA genes were annotated using the tRNAscanSE program [57]. Intron boundaries were located by modeling intron secondary structures [32,56] and by comparing the sequences of intron-containing genes with those of intron-less homologues using FRAMEALIGN of the Wisconsin package. Circle graphs were generated using the CGView program [57].

Phylogenetic analysis was conducted using forty-two cp protein sequences $(a t p A, a t p B, a t p E, a t p F, a t p H, p e t B, p e t D, p e t G, p s a A, p s a B$, psaC, psaf, psbA, psbB, psbC, psbD, psbE, psbF, psbH, psbI, psbf, psbK, psbN, psb T, psbZ, rpl2, rpl14, rpl16, rpl20, rpl36, rps2, rps3, rps4, rps7, rpso, rps11, rps12, rps14, rps18, rps19, ycf3, and ycf4) from 31 algal/ land plant organisms (see Data $\mathrm{S} 1$ ). The concatenated protein sequences were aligned using the multiple sequence alignment tools in CLUSTAL X version 1.81 with the default settings [58]. The adjusted alignment after manual correction was used for phylogenetic analyses by maximum likelihood (ML) and maximum parsimony (MP) methods. ML trees were computed with PHYML 3.0 [59] under the cpREV45 $+\Gamma+\mathrm{I}$ model of amino acid substitutions [60] and bootstrap support for each node was calculated using 100 replicates. MP trees were calculated with MEGA 4.0 [61] by 1,000 bootstrap replications, which were obtained using the Close-Neighbor-Interchange algorithm. MEGA 4.0 was used for visualization and printing of the trees.

\section{Supporting Information}

Data S1 Algal and land plant chloroplast genomes examined in the phylogenetic analyses

Found at: doi:10.1371/journal.pone.0014663.s001 (0.02 MB DOC)

\section{Author Contributions}

Conceived and designed the experiments: FL GW. Performed the experiments: FL WX CT. Analyzed the data: FL WX GW. Contributed reagents/materials/analysis tools: FL JN GP SH. Wrote the paper: FL.
4. Goremykin VV, Holland B, Hirsch-Ernst KI, Hellwig FH (2005) Analysis of Acorus calamus chloroplast genome and its phylogenetic implications. Mol Biol Evol 22(9): 1813-1822.

5. Pombert JF, Otis C, Lemieux C, Turmel M (2005) The chloroplast genome sequence of the green alga Pseudendoclonium akinetum (Ulvophyceae) reveals unusual structural features and new insights into the branching order of chlorophyte lineages. Mol Biol Evol 22(9): 1903-1918. 
6. Lemieux C, Otis C, Turmel M (2007) A clade uniting the green algae Mesostigma viride and Chlorokybus atmophyticus represents the deepest branch of the Streptophyta in chloroplast genome-based phylogenies. BMC Biology 5: 2.

7. Simpson CL, Stern DB (2002) The treasure trove of algal chloroplast genomes. surprises in architecture and gene content, and their functional implications. Plant Physiol 129: 957-966.

8. Koning AP de, Keeling PJ (2006) The complete plastid genome sequence of the parasitic green alga Helicosporidium sp. is highly reduced and structured. BMC Biology 4: 12.

9. Sugiura M (1992) The chloroplast genome. Plant Mol Biol 19: 149-168.

10. Karol KG, McCourt RM, Cimino MT, Delwiche CF (2001) The closest living relatives of land plants. Science 294: 2351-2353.

11. Turmel M, Otis C, Lemieux C (2002) The complete mitochondrial DNA sequence of Mesostigma viride identifies this green alga as the earliest green plant divergence and predicts a highly compact mitochondrial genome in the ancestor of all green plants. Mol Biol Evol 19: 24-38.

12. Turmel M, Otis C, Lemieux G (1999) The complete chloroplast DNA sequence of the green alga Nephroselmis olivacea: insights into the architecture of ancestral chloroplast genomes. Proc Natl Acad Sci USA 96: 10248-10253.

13. Robbens S, Derelle E, Ferraz C, Wuyts J, Moreau H, et al. (2007) The complete chloroplast and mitochondrial DNA sequence of Ostreococcus tauri: organelle genomes of the smallest eukaryote are examples of compaction. Mol Biol Evol 24(4): 956-968.

14. Turmel M, Gagnon MC, O'Kelly CJ, Otis C, Lemieux C (2009) The chloroplast genomes of the green algae Pyramimonas, Monomastix, and Pycnococcus shed new light on the evolutionary history of prasinophytes and the origin of the secondary chloroplasts of euglenids. Mol Biol Evol 26(3): 631-648.

15. Wakasugi T, Nagai T, Kapoor M, Sugita M, Ito M, et al. (1997) Complete nucleotide sequence of the chloroplast genome from the green alga Chlorella vulgaris: the existence of genes possibly involved in chloroplast division. Proc Natl Acad Sci USA 94(11): 5967-5972.

16. de Cambiaire JC, Otis C, Turmel M, Lemieux C (2007) The chloroplast genome sequence of the green alga Leptosira terrestris: multiple losses of the inverted repeat and extensive genome rearrangements within the Trebouxiophyceae. BMC Genomics 8(1): 213 .

17. Pombert JF, Lemieux C, Turmel M (2006) The complete chloroplast DNA sequence of the green alga Oltmannsiellopsis viridis reveals a distinctive quadripartite architecture in the chloroplast genome of early diverging ulvophytes. BMC Biology 4: 3.

18. Maul JE, Lilly JW, Cui L, dePamphilis CW, Miller W, et al. (2002) The Chlamydomonas reinhardtii plastid chromosome: islands of genes in a sea of repeats. Plant Cell 14(11): 2659-2679.

19. de Cambiaire JC, Otis C, Lemieux C, Turmel M (2006) The complete chloroplast genome sequence of the chlorophycean green alga Scenedesmus obliquus reveals a compact gene organization and a biased distribution of genes on the two DNA strands. BMC Evol Biol 6: 37.

20. Bélanger AS, Brouard JS, Charlebois P, Otis C, Lemieux C, et al. (2006) Distinctive architecture of the chloroplast genome in the chlorophycean green alga Stigeoclonium helveticum. Mol Genet Genomics 276(5): 464 477.

21. Brouard JS, Otis C, Lemieux C, Turmel M (2008) Chloroplast DNA sequence of the green alga Oedogonium cardiacum (Chlorophyceae): Unique genome architecture, derived characters shared with the Chaetophorales and novel genes acquired through horizontal transfer. BMC Genomics 9: 290

22. Salganik RI, Dudareva NA, Kiseleva EV (1991) Structural organization and transcription of plant mitochondrial and chloroplast genomes. Electron Microscopy Reviews 4(2): 221-247.

23. Kolodner R, Tewari KK (1975) The molecular size and conformation of the chloroplast DNA from higher plants. Biochim Biophys Acta 402: 372-390.

24. Deng XW, Wing RA, Gruissem W (1989) The chloroplast genome exists in multimeric forms. Proc Natl Acad Sci USA 86: 4156-4160.

25. Karyn D, Scissum-Gunn, Medha GSB, Brent LN (1998) Separation of different conformations of plant mitochondria DNA molecules by field inversion gel electrophoresis. Plant Mol Biol Rep 16: 219-229.

26. Lilly JW, Havey MJ, Jason SA, Jiang J (2001) Cytogenomic analyses reveal the structural plasticity of the chloroplast genome in higher plants. The Plant Cell 13: $245-254$

27. Delene JO, Arnold JB (2004) Most chloroplast DNA of maize seedlings in linear molecules with defined ends and branched forms. J Mol Biol 335: 953-970.

28. Olderburg D, Bendich A (1996) Size and structure of replicating mitochondrial DNA in cultured tobacco cells. Plant Cell 8: 447-461.

29. Kim GH, Tatiana AK, Kang YM (2001) Life without a cell membrane: regeneration of protoplasts from disintegrated cells of the marine green alga Bryopsis plumosa. J Cell Sci 114: 2009-2014.

30. Ye NH, Wang GC, Wang FZ, Zeng CK (2005) Formation and growth of Bryopsis hypnoides Lamouroux regenerated from its protoplasts. J Inte Plant Biol 47(7): 856-862.

31. Burr FA, West JA (1970) Light and electron microscope observations on the vegetative and reproductive structures of Bryopsis hypnoides. Phycologia 9: 17-37.
32. Michel F, Westhof E (1990) Modelling of the three-dimensional architecture of group I catalytic introns based on comparative sequence analysis. J Mol Biol 216(3): 585-610

33. Hagopian JC, Reis M, Kitajima JP, Bhattacharya D, de Oliveira MC (2004) Comparative analysis of the complete plastid genome sequence of the red alga Gracilaria tenuistipitata var. liui provides insights into the evolution of rhodoplasts and their relationship to other plastids. J Mol Evol 59(4): 464-477.

34. Wang GC, Tseng CK (2006) Culturing the segments of Bryopsis hypnoides Lamouroux thalli regenerated from protoplast aggregations. J Inte Plant Biol 48(2): 190-196.

35. Li DM, Lü F, Wang GC, Zhou BC (2009) Assembly of the subcellular parts of Bryopsis hypnoides Lamouroux into new protoplasts. Russ J Plant Physl 56(1): $110-117$.

36. Trench RK, Greene RW, Bystrom BG (1969) Chloroplast as functional organelles in animal tissues. J Cell Biol 42: 404 417.

37. Trowbridge CD (1991) Diet specialization limits herbivorous sea slug's capacity to switch among food species. Ecology 72(5): 1880-1888.

38. Martin A, Ros JD (1992) Dynamics of a peculiar plant-herbivore relationship: the photosynthetic ascoglossan Elysia timida and the chlorophycean Acetabularia acetabulum. Mar Biol 112: 677-682.

39. Lee RE (1999) Phycology, Ed 3. Cambridge: Cambridge University Press. 226 p.

40. Green BJ, Li WY, Manhart JR, Fox TC, Summer EJ, et al. (2000) Mollusc-algal chloroplast endosymbiosis. Photosynthesis, thylakoid protein maintenance, and chloroplast gene expression continue for many months in the absence of the algal nucleus. Plant Physiol 124: 331-342.

41. Rumpho ME, Summer EJ, Manhart JR (2000) Solar-powered sea slugs, Mollusc/algal chloroplast symbiosis. Plant Physiol 123: 29-38.

42. Rumpho ME, Worful JM, Lee J, Kannan K, Tyler MS, et al. (2008) Horizontal gene transfer of the algal nuclear gene $p s b O$ to the photosynthetic sea slug Elysia chlorotica. Proc Natl Acad Sci USA 105(46): 17867-17871.

43. Lehman RL, Manhart JR (1997) A preliminary comparison of restriction fragment patterns in the genus Caulerpa (Chlorophyta) and the unique structure of the chloroplast genome of Caulerpa sertulariodes. J Phycol 33(6): 1055-1062.

44. Manhart JR, Kelly K, Dudock BS, Palmer JD (1989) Unusual characteristics of Codium fragile chloroplast DNA revealed by physical and gene mapping. Mol Gen Genet 216(2-3): 417-421.

45. Wolfe KH, Morden CW, Palmer JD (1992) Function and evolution of a minimal plastid genome from a nonphotosynthetic parasitic plant. Proc Natl Acad Sci USA 89: 10648-10652.

46. Glöckner G, Rosenthal A, Valentin K (2000) The structure and gene repertoire of an ancient red algal plastid genome. J Mol Evol 51: 382-390.

47. BacKert S, Dorfel P, Börner T (1995) Investigation of plant organellar DNAs by pulsed-field gel electrophoresis. Curr Genet 28: 390-399.

48. Palmer JD, Thompson WF (1982) Chloroplast DNA rearrangements are more frequent when a large inverted repeat sequence is lost. Cell 29: 537-550.

49. Kolodner R, Tewari KK (1979) Inverted repeats in chloroplast DNA of higher plants. Proc Natl Acad Sci USA 76: 41-45.

50. Friedl T, O'Kelly CJ (2002) Phylogenetic relationships of green algae assigned to the genus Planophila (Chlorophyta): evidence from 18S rDNA sequence data and ultrastructure. Eur J Phycol 37: 373-384.

51. Pombert JF, Otis C, Lemieux C, Turmel M (2004) The complete mitochondrial DNA sequence of the green alga Pseudendoclonium akinetum (Ulvophyceae) highlights distinctive evolutionary trends in the Chlorophyta and suggests a sister-group relationship between the Ulvophyceae and Chlorophyceae. Mol Biol Evol 21: 922-935.

52. Gordon D, Abajian C, Green P (1998) Consed: a graphical tool for sequence finishing. Genome Res 8: 195-202.

53. Sambrook J, Russell DW (2001) Molecular cloning: A Laboratory Manual. Ed 3. New York: Cold Spring Harbor Laboratory Press.

54. Tian C, Wang GC, Ye NH, Zhang BY, Fan XL, et al. (2005) Cloning and sequence analysis of the partial sequence of the $r b c L$ from Bryopsis hypnoides. Acta Oceanologica Sinica 24(5): 150-161

55. Lowe TM, Eddy SR (1997) tRNAscan-SE: a program for improved detection of transfer RNA genes in genomic sequence. Nucleic Acids Res 25: 955-964.

56. Michel F, Umesono K, Ozeki H (1989) Comparative and functional anatomy of group II catalytic introns-a review. Gene 82(1): 5-30.

57. Grant JR, Stothard P (2008) The CGView Server: a comparative genomics tool for circular genomes. Nucleic Acids Res 36: 181-184.

58. Thompson JD, Gibson TJ, Plewniak F, Jeanmougin F, Higgins DG (1997) The CLUSTAL windows interface: flexible strategies for multiple sequence alignment aided by quality analysis tools. Nucleic Acids Res 24: 4876-4882.

59. Guindon S, Gascuel O (2003) A simple, fast, and accurate algorithm to estimate large phylogenies by maximum likelihood. Syst Biol 52(5): 696-704.

60. Adachi J, Waddell PJ, Martin W, Hasegawa M (2000) Plastid genome phylogeny and a model of amino acid substitution for proteins encoded by chloroplast DNA. J Mol Evol 50: 348-358.

61. Tamura K, Dudley J, Nei M, Kumar S (2007) MEGA4: molecular evolutionary genetics analysis (MEGA) software version 4.0. Mol Biol Evol 24(8): 1596-1599. 